\title{
Aerodynamic Interference Due to MSL Reaction Control System
}

\author{
Artem A. Dyakonov;, Mark Schoenenberger \\ NASA LaRC, Hampton, Virginia, 23681, USA \\ William I. Scallion $\$$ John W. Van Norman, § Luke A. Novak, ๆ \\ AMA, Hampton, Virginia, 23666, USA \\ and Chun Y. Tang" \\ NASA ARC, Moffet Field, California, 94035, USA
}

\begin{abstract}
An investigation of effectiveness of the reaction control system (RCS) of Mars Science Laboratory (MSL) entry capsule during atmospheric flight has been conducted. The reason for the investigation is that MSL is designed to fly a lifting actively guided entry with hypersonic bank maneuvers, therefore an understanding of RCS effectiveness is required. In the course of the study several jet configurations were evaluated using Langley Aerothermal Upwind Relaxation Algorithm (LAURA) code, Data Parallel Line Relaxation (DPLR) code, Fully Unstructured 3D (FUN3D) code and an Overset Grid Flowsolver (OVERFLOW) code. Computations indicated that some of the proposed configurations might induce aero-RCS interactions, sufficient to impede and even overwhelm the intended control torques. It was found that the maximum potential for aero-RCS interference exists around peak dynamic pressure along the trajectory. Present analysis largely relies on computational methods. Ground testing, flight data and computational analyses are required to fully understand the problem. At the time of this writing some experimental work spanning range of Mach number 2.5 through 4.5 has been completed and used to establish preliminary levels of confidence for computations. As a result of the present work a final RCS configuration has been designed such as to minimize aero-interference effects and it is a design baseline for MSL entry capsule.
\end{abstract}

\section{Nomenclature}

$a_{n} \quad$ Viking base correction coefficients

$C_{A} \quad$ Axial force coefficient

$C_{p} \quad$ Pressure coefficient

$C_{D}$ Drag coefficient

$C G$ Center of mass

$M \quad$ Axis moment, $\mathrm{Nm}$

$P \quad$ Pressure, $\mathrm{Nm}^{2}$

$\alpha \quad$ Angle of attack, degrees

$\beta \quad$ Angle of sideslip, degrees

Subscript

$b$ base

$\infty$ free-stream

*Aerospace Engineer, Atmospheric Flight Entry Systems Branch, AIAA Member.

$\dagger$ Aerospace Engineer, Atmospheric Flight Entry Systems Branch, AIAA Member.

¥Consultant, Aerothermodynamics Branch.

§Senior Project Engineer, Atmospheric Flight Entry Systems Branch, AIAA Member.

IStaff Engineer, Atmospheric Flight Entry Systems Branch, AIAA Member.

\| Aerospace Engineer, Reacting Flow Environments Branch, AIAA Member. 


\section{Introduction}

The next generation of Mars exploration landers must precisely deliver scientific payloads to sites of interest, unlike previous Mars missions. The past missions, such as Viking and Pathfinder, performed landings to within 100s of kilometers from their targets using an unguided atmospheric entry. Guided entry of a capsule with a relatively high lift-to-drag ratio will allow landing to within $10 \mathrm{~s}$ of kilometers from the target with a significantly more massive payload. Guided lifting entry requires the use of a reaction control system (RCS) for both attitude correction and entry guidance maneuvers. Various aspects of the entry, descent and landing (EDL) system performance may be impacted by the operation of the RCS during entry. Mars Science Laboratory (MSL) is the first entry system designed for actively guided entry at Mars. MSL will use its reaction control system throughout most of the entry, including hypersonic and supersonic regimes, as required. This paper illustrates the risks that arise from the gasdynamic interaction of the entry vehicle's flowfield and RCS, and which require attention in the areas of aerodynamics and control, and aerothermal environments. This paper will review the methods to address the design challenges associated with integration of RCS into the atmospheric entry system on the example of MSL. Among these challenges is the analysis of the potential for the aerodynamic interference due to both the direct jet plume impingement and more complex plume interactions with the wake flow. Design solutions that mitigate interaction effects will be discussed.

\section{Background}

As MSL capsule enters atmosphere, it interacts with the surrounding gas. The interaction produces aerodynamic forces and moments that act on the vehicle during entry, and in the process reduce the vehicle kinetic energy to an acceptable value for the deployment of the parachute. Interactions between the entry vehicle and the surrounding flow, which are of importance here, occur during hypersonic and supersonic flight. In these regimes, flow around the capsule is characterized by the presence of a bow shock ahead of the capsule, multiple expansion waves around the shoulder, a massively separated wake flow, and a complex recompression shock system behind the vehicle as shown in figure 1 .

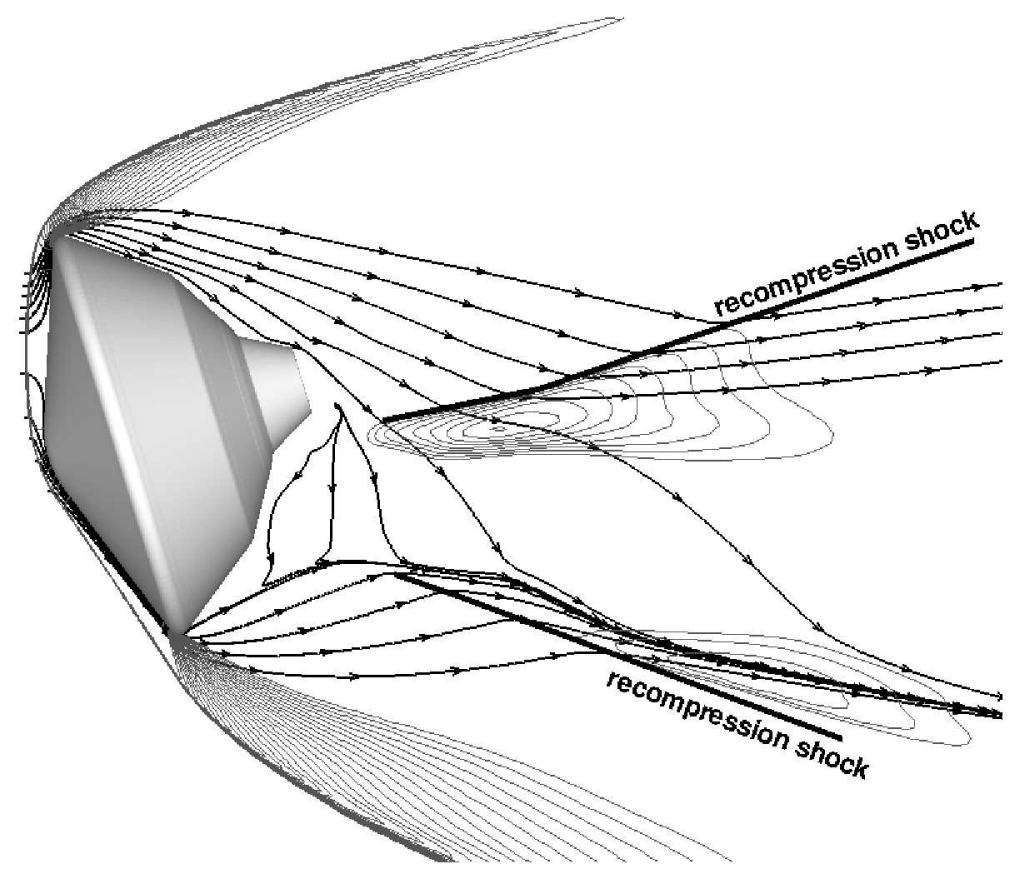

Figure 1. Flow around MSL capsule at Mach 18.1 
MSL is equipped with Reaction Control System (RCS), which will enable rate damping and bank maneuvers during entry. Because RCS jets exit into the complex aftbody flow, they will induce diverse flow interaction phenomena, for example like shown in the figure 2. These interactions may alter aerodynamic characteristics and aerothermodynamic environment of the backshell of the capsule however this paper will focus mainly on analysis of the former, i.e. the induced aerodynamic moments, which impact RCS effectiveness. The objective is to determine the cumulative effect of changes in the basecover pressure distribution on RCS control authority so that the interference moment can be determined.

$$
M_{\text {interference }}=C x_{\text {interference }} \cdot S_{r e f} \cdot L_{r e f} \cdot \frac{1}{2} \rho v^{2}
$$

where

$$
C x_{\text {interference }}=C x_{R C S}-C x_{B a s e l i n e}
$$

This interference moment can be in the axis of the active RCS thruster, in which case it contributes to RCS gain, or to one of the other two axes, in which case it produces cross coupling.

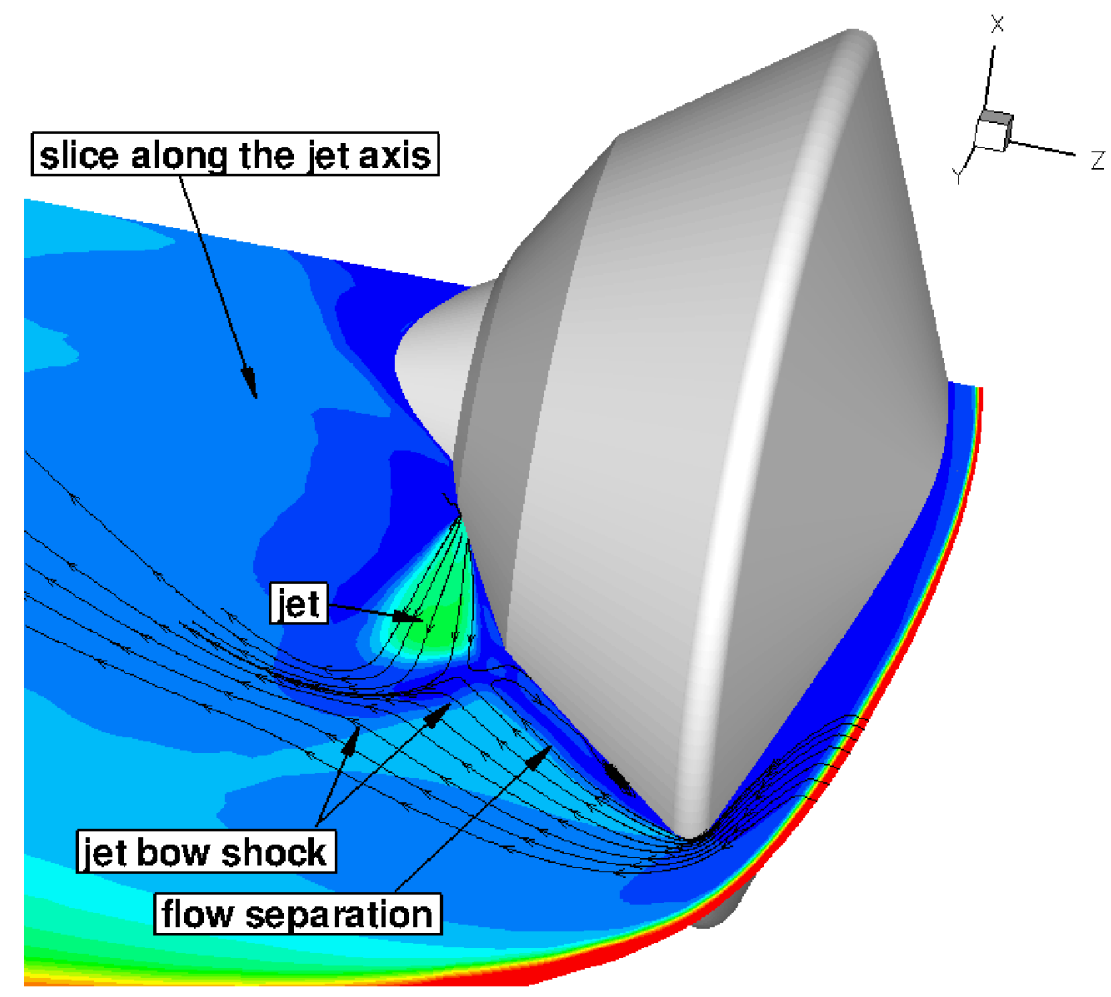

Figure 2. Jet-wake interaction

\section{Aero-RCS Heritage}

There is a significant generation gap in NASA's use of blunt capsules for space exploration. Capsules of the 60's and 70's (Mercury/Gemini, Apollo and Viking) have flown successful controlled unguided and guided entries into Earth and Mars atmospheres. In the early 80's the Space Shuttle took over the task of flying people and cargo into Earth's orbit and it was viewed as more versatile and capable, thus ending the use by NASA of capsules for manned flights near Earth. Presently the Crew Exploration Vehicle (CEV) is slated to be a replacement for the Space Shuttle orbiter and will return a capsule - based architecture to human flights near Earth and to the Moon.

Since the two successful landings of Viking 1 and 2 in 1976, landings on Mars have seized for twenty years. A small and a comparatively simple mission, Mars Pathfinder, landed on Mars in 1997 and marked the renewed interest in Mars surface exploration. MPF was followed by larger and more complex MER Spirit 
and Opportunity in 2004 which are operational today. Capsules of these relatively recent missions were spin-stabilized and did not use controlled entry. Two other recent missions to Mars (Mars Polar Lander and Mars Phoenix) have used RCS for attitude rate control and azimuth alignment. It is unclear what happened to Mars Polar Lander which was due to land in December of 1999, but its sister ship Phoenix underwent significant system-wide changes, as compared to MPL, and has been launched in 2007 for a successful landing in 2008. For the purposes of this report Phenix is viewed as a current mission and not a prior mission, and the analysis of the effectiveness of its RCS is presented in a separate publication. ${ }^{1}$ Because none of the recently flown 3-axis stabilized spacecraft (MPL and Phoenix) had any instrumentation to help measure RCS effects in flight, and all other recent flights were not controlled, any inquiry into heritage data on RCS aeroheating and control interference for blunt capsules should be addressed to prior missions, such as Apollo and Viking, which used RCS during entry and do have some limited data. Below is the brief summary of the types of data and findings.

\section{A. Apollo Program}

Limited data is available from the Apollo Program. Most of the Project's focus was on the aeroheating. The program carried out ground testing of aeroheating augmentation due to RCS jets using the then-new phase change coating technique. Results of that work are summarized by Jones and Hunt. ${ }^{2}$ Authors found that the interference heating on the Apollo shape was significant for yaw and roll jets. Interference heating in the case of the yaw and roll jets covered significant acreage of the backshell inddicating large changes to the aftbody environment. In particular, forward-firing roll jets produced the most energetic interaction with the shear layer, coming off of the capsule's shoulder, and this yielded the greatest heating augmentation over the largest area, which should have produced a change in capsule moments due to increased pressure in the interaction zone.

In addition to wind tunnel testing, Apollo entry capsules were instrumented to measure surface heating in flight. Heating rate spikes on the lee-side of the spacecraft during entry were found to correspond to RCS jet firings and amounted to about a factor of 5 times the nominal measurement. ${ }^{3}$ The utility of this data to present day numerical simulations is being assessed.

There were no tests to look at the effect of RCS jets on aerodynamics of Apollo capsules. The only mention of aero-RCS interference is in reference to the flight of Apollo 7, which saw "considerable pitch and yaw control activity in the transonic region during the final 2 min before drogue deployment", which was attributed to winds and thruster-flow interference. ${ }^{4}$

\section{B. Viking Program}

Viking program has made an attempt to measure experimentally the magnitude of jet-aerodynamic interference. A test was conducted in NASA Langley helium Mach 20 wind tunnel, where thruster plumes were simulated as solid bodies. This test did not net any significant insight into the jet-wake interference partly because of the insufficient accuracy of the data. ${ }^{5}$ It was suggested, that the test be repeated with a balance, designed to measure smaller moments, but this was never carried out. To the credit of the Viking team it should be noted that the Viking RCS truster layout should produce little if any aerodynamic interference based on today's understanding of the phenomena.

No attempts were made by Viking Project to measure aeroheating augmentation due to jets because aftbody heating was not expected to be significant. ${ }^{6}$ Viking was entered into Mars atmosphere from a circular orbit at a relative velocity of about $4.6 \mathrm{~km} / \mathrm{sec}$. Low speed entry of a capsule with a relatively low ballistic coefficient $\left(\mathrm{m} / C_{D} A=63.7\right)$ resulted in very low heat fluxes on the aft-cover. Because these heatfluxes were low, on the order of $1 \mathrm{Watt} / \mathrm{cm}^{2}$, it was possible to make the aft-cover of aluminum, and not cover it with thermal protection material. Use of the small 8lbf thrusters for rate damping and for lift vector alignment would not produce the heat fluxes and heat loads much beyond the baseline. Therefore, it was not essential for Viking to analyze RCS aeroheating augmentation.

\section{Space Shuttle Orbiter}

Space Shuttle Orbiter is a lifting body winged vehicle and does not share aerodynamic characteristics with blunt entry capsules. Its experience is, however, valuable because of the insight gained in the course of ground 
tests and flight operations. The Program carried out multiple wind tunnel experiments to characterize jetaerodynamic interaction and to determine control effectiveness during entry. Flight data is also available from which to infer control effectiveness. Scallion has performed an analysis of the Shuttle post-flight and wind tunnel data with an excellent overview of a number of findings. ${ }^{7}$ He stressed the importance of the thruster plume shape and of the momentum ratio in order to achieve a correct magnitude of aerodynamic interaction based on observed performance. Because of the large amount of available wind tunnel and flight data it would be beneficial to validate numerical tools against these data sources.

\section{Recent Testing}

Renewed interest in guided blunt capsules for both robotic and manned missions resulted in new tests to determine both the aeroheating augmentation and control interference due to jets. Of the three missions, designed to use RCS during entry (Phoenix, MSL and CEV CM), MSL and CEV initiated experimental programs. Phoenix could not, due to various reasons, undertake such a program, and relied heavily on computational analyses. MSL focused its efforts on collecting data on interference of jets with capsule's aerodynamics at supersonic and hypersonic speeds. CEV has designed and carried out tests of aeroheating augmentation interaction of jets with local flow. All these tests are being analysed toward validation of computational tools. Wind tunnel models in these tests use derivatives of the nozzle scaling methodology, outlined by Pindzola. ${ }^{23}$

\section{A. MSL Unitary Tunnel Test}

Because of the key role RCS will play in entry, descent and landing (EDL) of MSL, the Project pursued an experimental program to measure aerodynamic RCS interference. Work was done at NASA Langley Research Center Unitary Plan Wind Tunnel (UPWT). The first round of tests focused on the supersonic (below Mach 4.5) performance, and data was collected at Mach 2.5, 3.5 and 4.5 for a range of Reynolds numbers and jet pressure ratios. Ambient gas was air, perfect gas, and nitrogen was used as jet effluent. data was collected for the individual firings of pitch, yaw and roll jets, and combination firings. Model design for this test reflected the then current MSL entry vehicle (outer mold-line designation 6) and the then current RCS system layout. The data, collected in this test series was compared with CFD predictions (LAURA and FUN3D) and the results were used as an estimate of confidence in numerical predictions. ${ }^{8}$ Model nozzles were conical with a 10-degree half-angle of the divergent section. Throat diameter, nozzle half-angle and nozzle chamber pressures were selected to produce jet plumes as closely scaled to those in flight as possible. The model was mounted on a six-component balance (designated SS12), whose axial force channel was sacrificed to make room for nitrogen supply into the model, making it into a five-component balance.

\section{B. CEV 31-inch Mach 10 Test Data}

Series of experiments using temperature sensitive paint (TSP) and pressure sensitive paint (PSP) were carried out in LaRC Mach 10 facility to determine aeroheating augmentation due to firing of jets. Modular SLA model was designed to accommodate a range or jet configurations. ${ }^{11}$ The results of these tests are being compared with numerical predictions to determine the uncertainty in aeroheating predictions. This series of tests is the first of the kind since the work of Jones and Hunt ${ }^{2}$ was conducted and provides an invaluable insight into the jet-wake interaction.

\section{MSL Mach 10 Tunnel Test}

MSL RCS configuration has changed three times since it's been tested in the UPWT. Aftshell geometry also has changed. The final configuration of the aeroshell and RCS was tested in the Langley Mach 10 tunnel to confirm the design changes. The reason for testing at Mach 10 is that the highest aero-RCS interference effects are expected in flight at hypersonic speeds, near peak dynamic pressure. Tests at Mach 10 were conducted in a perfect gas facility flowing air, and nitrogen was used as jet effluent. data was collected for the individual firings of pitch, yaw and roll jets, and combination firings. Nozzle fliw was scaled to reflect a representative flight condition. The data collected in this test series is in process of being compared to the CFD predictions. ${ }^{8}$ 


\section{Evolution of MSL RCS Configuration}

Mars Science Laboratory RCS has evolved under the influence of a a wide range of constraints. Initial configuration had thrusters arranged as shown in the figure 3 . Thrusters provided nearly independent torques about all three axes and their layout idea was fairly analogous to the one, used by Viking landers shown for reference in the figure 4.

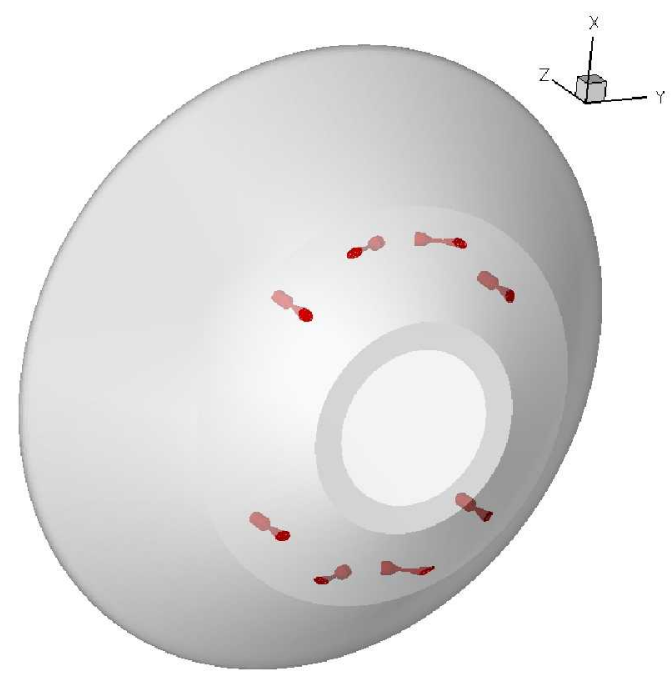

Figure 3. View of RCS layout of OML 6 model showing roll and pitch-yaw nozzles

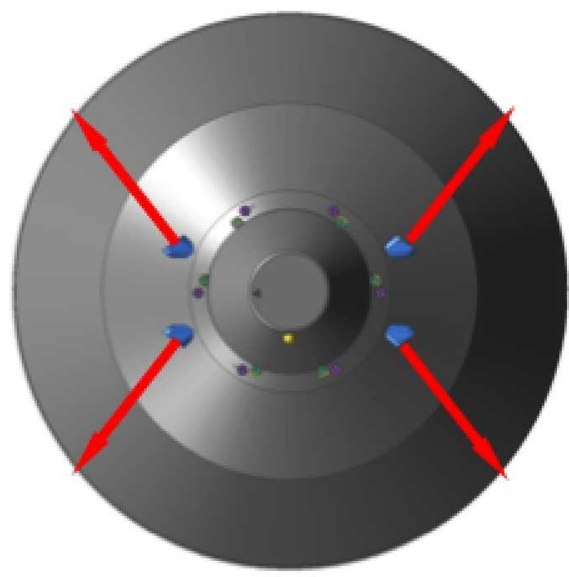

Figure 5. Second iteration of RCS

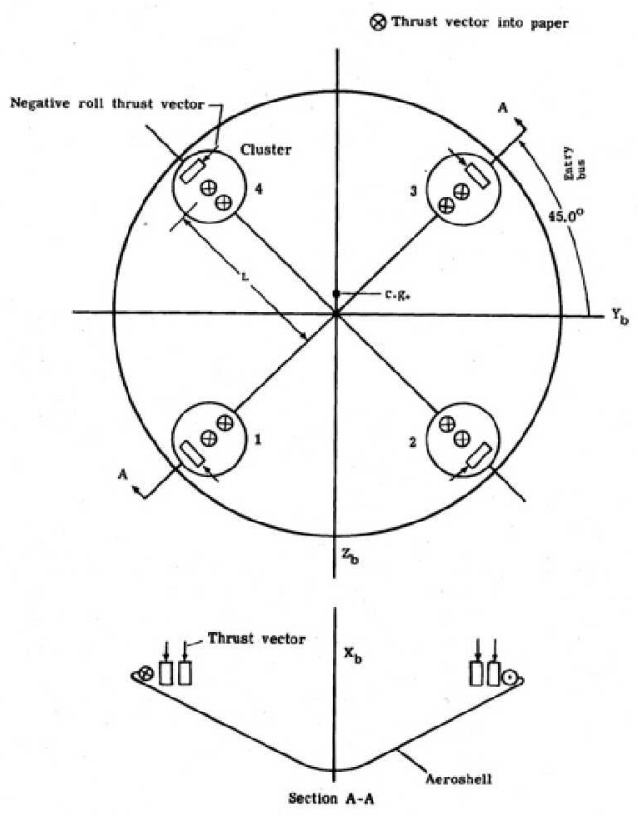

Figure 4. Viking $\operatorname{RCS}^{12}$

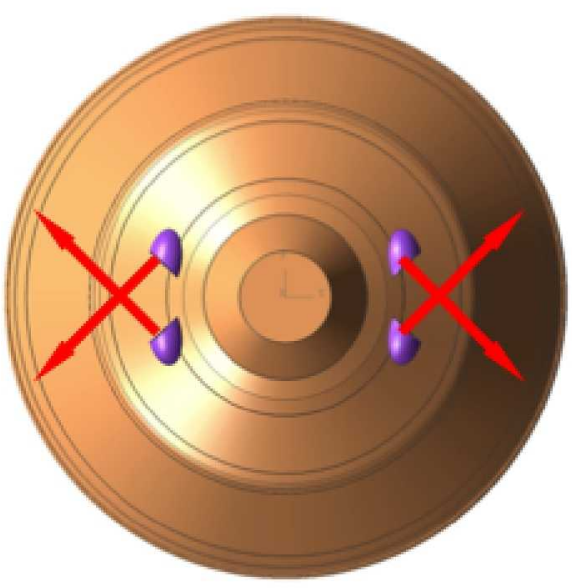

Figure 6. Third iteration of RCS

In an effort to avoid interaction of RCS plumes with the parachute risers, the thrusters were moved to the rear of the capsule and oriented away from the capsule's centerline (figure 5). At about the same time the capsule has grown an added rear volume to cover parachute mortar, also shown in the figure. This configuration was extensively studied for aerothermal and aerodynamic RCS interactions. Primary concern has been the enhanced heating due to the windward thruster. ${ }^{9}$ Flowfield interaction of the windward thruster plume is shown in the figure 2. Additionally, because of the relatively high angle of attack of MSL capsule 
much of the windside aftbody sees attached hypersonic flow, as shown in the figure 1. Figure 7 shows the local flow environment, indicating possibility of attached approaching flow.

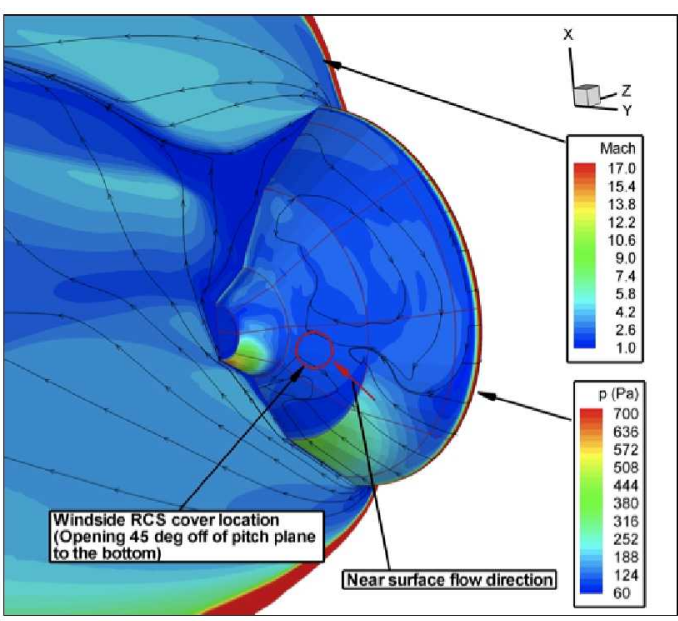

Figure 7. Flow environment

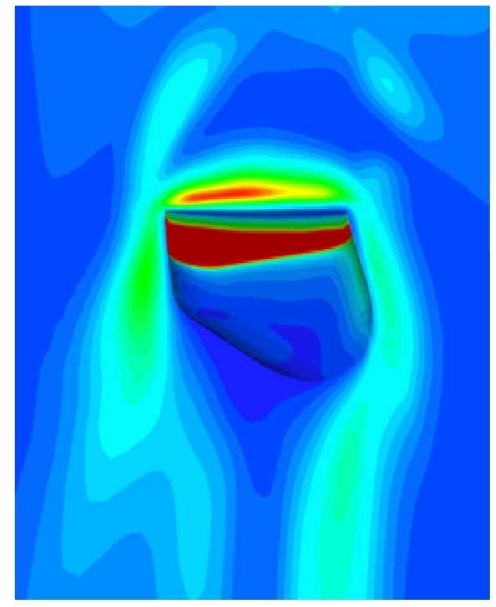

Figure 8. RCS cover heating

Figure 8 shows RCS cover in a representative local flow (rotated so the flow is top-to-bottom). As the figure indicates, this thruster configuration left the exposed nozzle openings in the path of high-energy attached flow and no a solution could be found to protect nozzles from overheating. An alternative solution was to swap the places of the windside and leeside thrusters, such that covers could be used to protect the windward thrusters as shown in the figure 6. This configuration suffered from excessive RCS-induced aerodynamic moment when yaw thrusters were fired.

It was established that the RCS effluent mixes with the entire recirculating wake regardless of thruster orientation and it is not possible to avoid contact between RCS effluent and parachute hardware. Figure 9 shows a computed boundary of the RCS effluent. Effluent fills all of the recirculation zone and gets convected aft as it mixes with the rest of the ambient gas. Because of this finding and due to the significant aerothermal and aerodynamic challenges posed by the RCS layouts in figures 5 and 6 the thruster layout was modified so as to minimize aero-RCS interference and aerothermal load on thrusters. The principle differences between

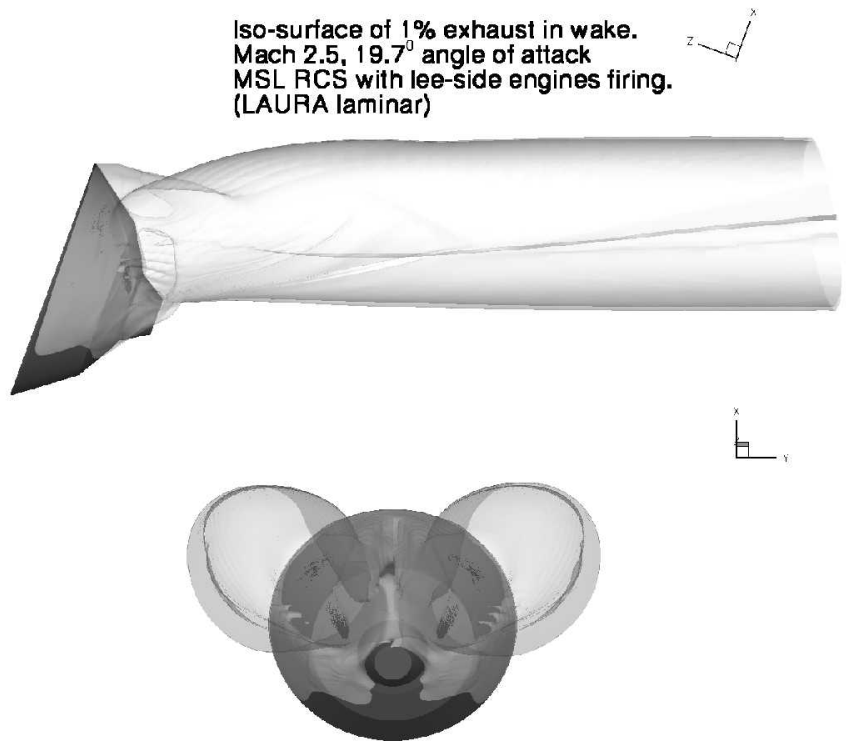

Figure 9. Thruster effluent mixing with the capsule's wake 
this final configuration and the one in the figure 6 are that the thrusters were rotated out of the base plane of the capsule, elliviating thruster interaction and they were moved outward to a wider location so as to allow thrust direction to cross the pitch plane ahead of the CG. The value of this aspect is discussed in the following sections.

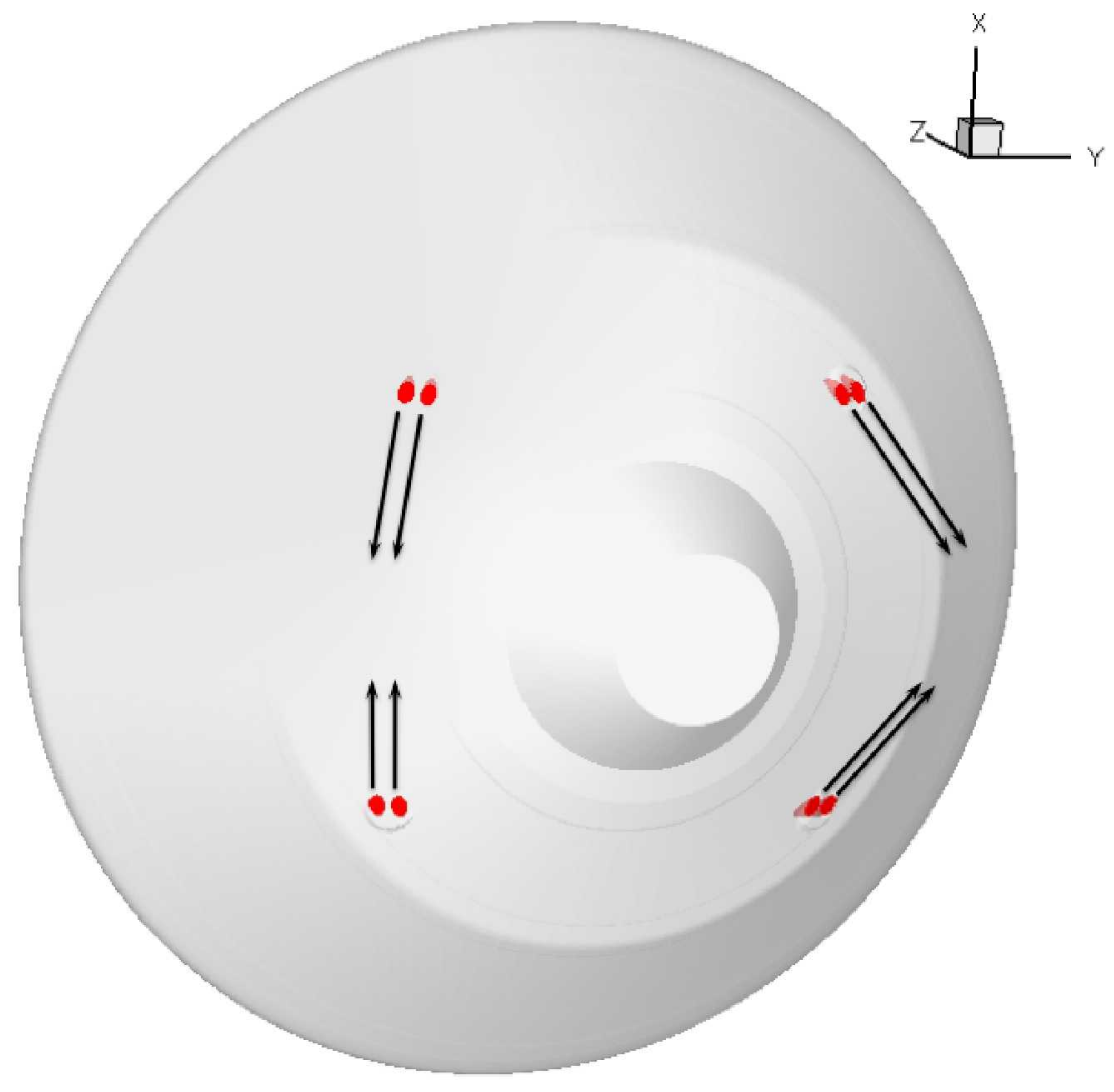

Figure 10. Final thruster arrangement of MSL RCS

\section{Aero-RCS Interference in Flight}

\section{A. Sources of RCS interference}

There are two main sources of RCS-Aero interaction. First, the under-expanded jet produces a change in near-exit flowfield, causing entrainment and reduction in pressure in he nearfield. If this jet impinges onto the surface, or collides with another jet, a local increase in surface pressure may result. This type of a near field interaction is relatively invarient with the trajectory condition, and is fairly easy to analyse. Second type of RCS interaction occurs due to the jet influencing the rest of the capsule wake flowfield, causing global changes in the capsule pressure field. This change is much more complex and it depends on the flight condition. Figure 11 shows the pressure distribution and a plume outline for one of screened RCS systems for MSL. In this system pairs of jets were mounted as shown (although only the thrusters of the right side are included in the figure) and the four right jets would be fired as shown to achieve yaw torque. The four jets formed a complex interaction flowfield with an impingement footprint in the near field that ws invarient with free-stream conditions. The four jets formed a larger plume that proceeded laterally to the side, which is near the bottom in the figure and interacted with the capsule's shear layer. The result was additional pressurization of the backshell surface near the shoulder. Large added pressure forces over broad acreage produced a moment that countered the intended yaw authority. Most of the interaction torque came from the pressurization near the shoulder. In this case all of the yaw authority was negated by the aerodynamic torques. Figure 12 shows the distribution over the aftshell of the yaw-axis moment arm. This gives an insight into the areas of hight sensitivity to local changes in pressure. Because some RCS activity produces 
unbalanced changes in the pressure distribution (like the example in the figure 11) it is beneficial to design the RCS such that the areas of high sensitivity are not affected by thrusters.

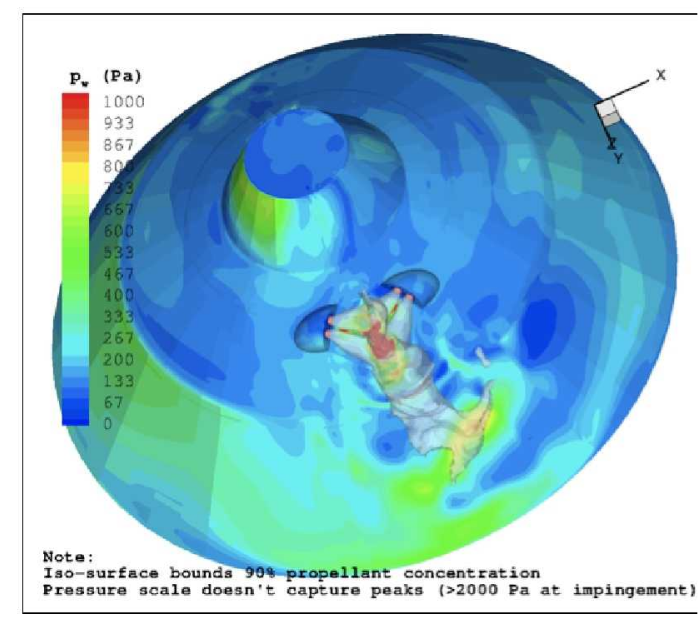

Figure 11. MSL aftbody pressure, yaw jets, candidate RCS layout, computed for Mach 18.1

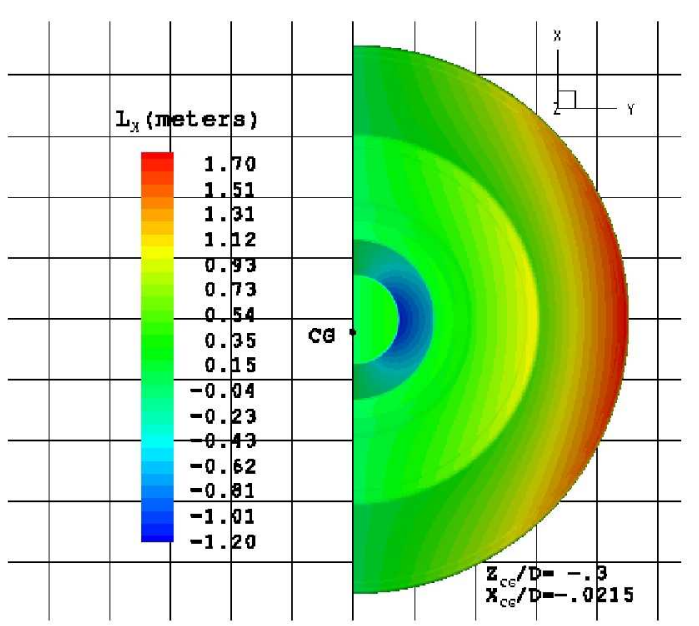

Figure 12. Aftshell surface yaw-moment arm distribution

\section{B. Aftbody pressure}

During most of the atmospheric entry the pressure on the aftbody of the capsule is significantly smaller then the forebody stagnation pressure. Very limited data exists, on which to base our understanding of base pressure of hypersonic capsules at Mars. Mitcheltree reconstructed aftbody pressure from Viking flight data and fit a polynomial of the form

$$
C_{p, b}=a_{0}+\frac{a_{1}}{M_{\infty}}+\frac{a_{2}}{M_{\infty}^{2}}+\frac{a_{3}}{M_{\infty}^{3}}
$$

where $a_{0}=8.325 E-3, a_{1}=1.1293 E-1, a_{2}=-1.801$ and $a_{3}=1.2885$ (see, for example, Schoenenberger ${ }^{8}$ ). This relation is currently applied to all Mars entry capsules to determine base pressure for aerodynamics. Figure 13 shows variation of the base pressure coefficient with Mach number. Base pressure coefficient is invarient with Mach for sufficiently high hypersonic mach numbers. This should make basecover pressure dependent on dynamic pressure alone in that regime. Equation (3) can be solved for pressure on the basecover as a function of Mach number on a representative MSL design entry trajectory. Figure 14 shows the variation of basecover pressure, as computed from Eq. (3) for two MSL entry trajectories. The seven points on the plot are CFD-predicted pressures. Generally, CFD follows the trend of the curve, but the magnitudes typically don't agree. This is a known issue with calculation of supersonic and hypersonic wakes of blunt base capsules, and is a subject of ongoing research. The plot in the figure 14 indicates two regions where aftbody pressures peak. One of these regions is at peak dynamic pressure on the trajectory (between Mach 15 and 20 depending on the trajectory profile) and another occurs during supersonic flight. These are the regions of most interest from the point of view of aero-RCS interactions because higher aftbody pressure is believed to amplify RCS-induced disturbances and produce higher interaction moments. This understanding has been applied to Phoenix, where analysis was carried out at rarefied, hypersonic and supersonic conditions. Low aftbody pressures at rarefied and early continuum regime negated any possible aero-RCS interaction, resulting in near-perfect thruster efficiency predicted for Phoenix before the onset of deceleration. ${ }^{1}$

\section{Effect of aftbody pressure on RCS interference}

Local pressure in the vicinity of the RCS jet is believed to play an important role in determining the extent to which surface environment will be affected by jet-flow interaction. Calculations indicate that the maximum interference effects occur at flight conditions near peak dynamic pressure on the trajectory, where aftbody 


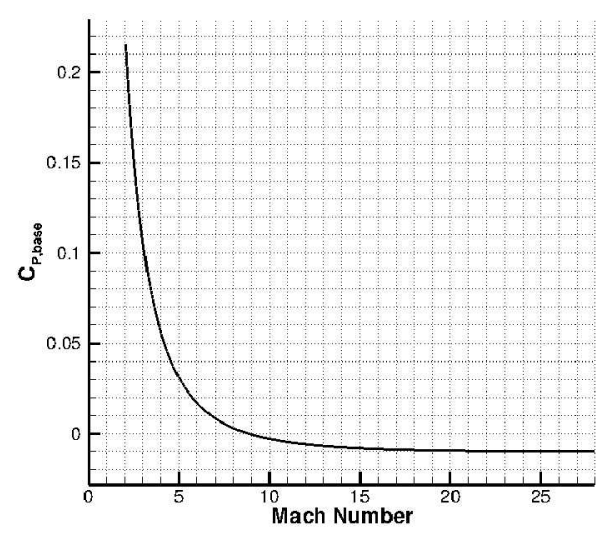

Figure 13. Variation of base pressure coefficient Figure 14. Variation of base pressure (solid) and with Mach number for blunt base capsule

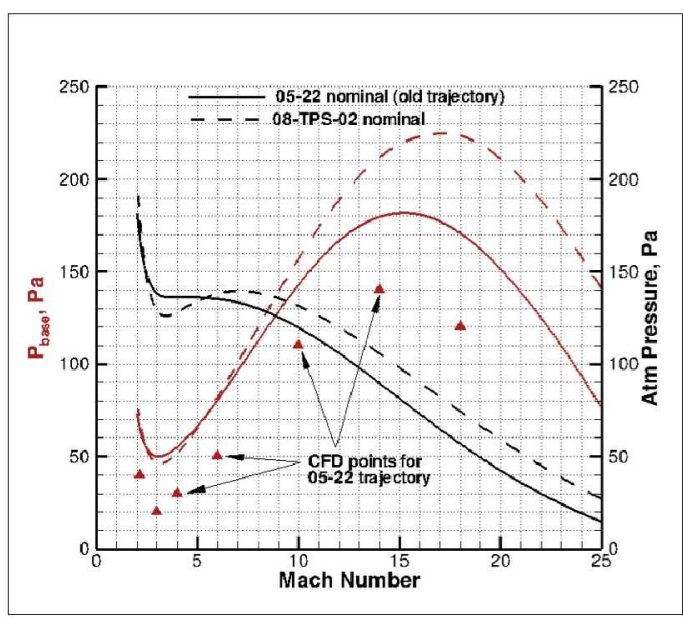
free-stream static pressure (dashed) with Mach number for blunt base capsule

pressure is maximum. Earlier in the trajectory, when the dynamic pressure is low there is simply no sufficient gas pressure on the aftbody to generate a significant interaction with a jet as was shown for Phoenix Lander. A somewhat similar effect occurs at much lower speeds, where a reduction in aftbody pressure on the left side of the dynamic pressure curve (see figures 15 and 16) reduces the effectiveness of any wake-RCS interactions. As the figures indicate, lower dynamic pressure of Mach 5 flight condition is not sufficient to produce any of the shock interaction phenomena, present in the Mach 18 solution. What remains a question is the fidelity of calculated trends in pressure over the rest of the separated flowfield.

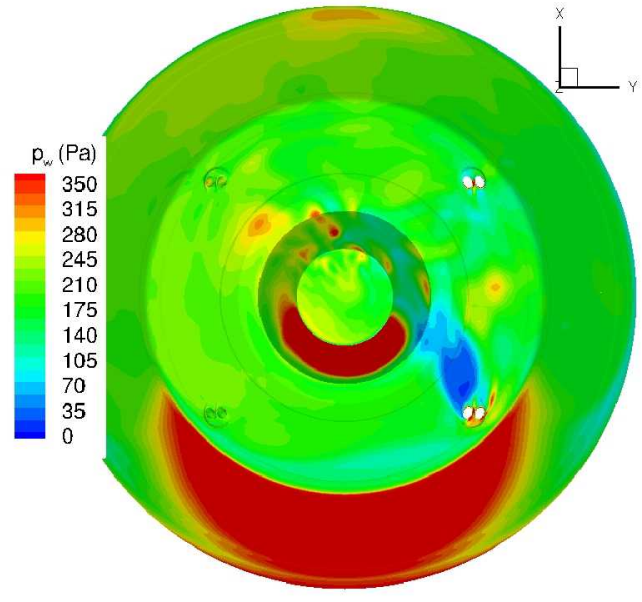

Figure 15. MSL aftbody pressure, yaw jets, com- Figure 16. MSL aftbody pressure, yaw jets, computed for Mach 18.1

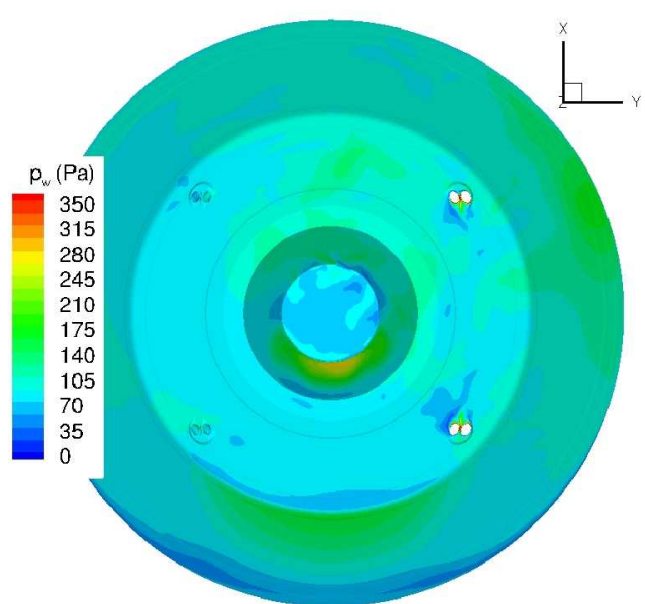

puted for Mach 5

Figure 15 illustrates typical interference pattern in presence of a jet: there's a compression front formed by the interaction of the underexpanded jet pair and the supersonic crossflow, and a shadow region, formed downstream of the jets. This pattern occurs in the area of the windside (lower) RCS jet pair, and it is not present in the area of the lee-side (upper) RCS jet pair. This should be the case, as the upper jets are in the area of fully separated flow (see, for example, figure 1, except that graphic is inverted in relation to 15 and 16). Heat flux is affected by the jets in a similar way as pressure, and generally most of the qualitative trends translate between heating and pressure. 


\section{Computational Analysis of RCS-Aerodynamic Effects in Flight}

An analysis of RCS-induced aerodynamic effects for the final iteration of thruster layout has been conducted at hypersonic, supersonic and transonic conditions. In this section some details of the methodology for flight calculations and the main findings are outlined.

\section{A. Hypersonic regime}

Laminar Navier-Stokes calculations at hypersonic conditions were carried out using LAURA ${ }^{13}$ code. Calculations included 8-specie non-equilibrium Mars gas (CO2, $\mathrm{CO}, \mathrm{N} 2, \mathrm{O} 2, \mathrm{NO}, \mathrm{C}, \mathrm{N}, \mathrm{O})$ plus ammonia (NH3) as a non-reacting RCS surrogate gas. Thruster effluent is composed of a mixture of $\mathrm{H} 2$, N2 and NH3, but the makeup is simplified. Two types of LAURA calculations were carried out: in the preliminary calculations the representative nozzle exit plane gas properties were obtained from CEA code and written into LAURA as a representative exit boundary condition. This type of a solution allowed for a quick turnaround necessary for configuration screening. Second round of calculations involved internal CFD domain that extended into the nozzle until the throat. Gas properties at throat were evaluated using CEA code and superimposed onto CFD solution. Grid complexity for the second type of calculations makes for significantly longer turnaround, rendering these solutions suitable only for the analyses of what's thought to be a reasonably established system. Figures 17 and 18 show CFD grid layouts for the third RCS layout and for the final layout. One-to-one block topology is required by LAURA, which adds significant complexity in such situations.

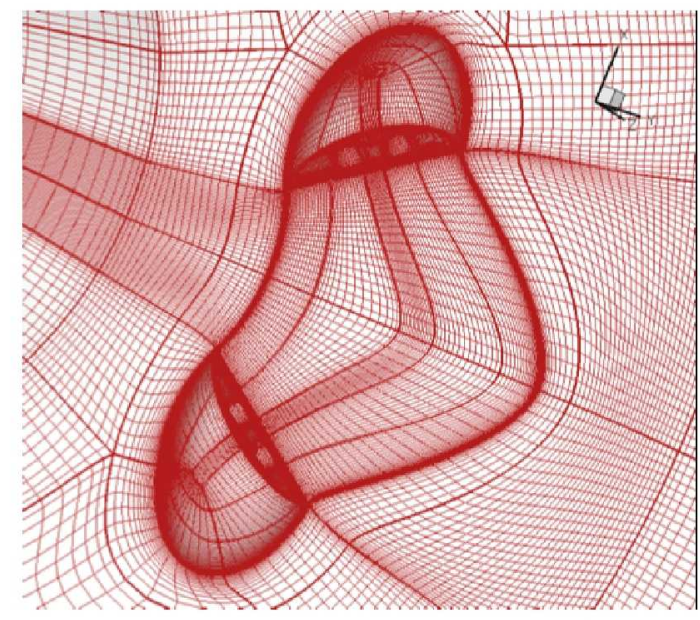

Figure 17. Nozzles in grid, configuration 3

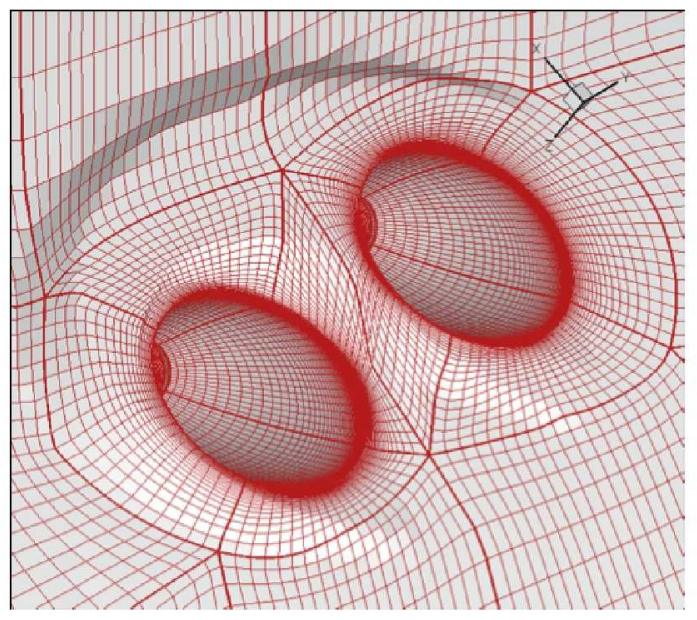

Figure 18. Nozzles in grid, final configuration

Calculations were carried out at Mach 18 flight condition for pitch-up, pitch-down, yaw and roll thrusters at an angle of attack of 17 degrees, which is representative of the expected MSL trim incidence during hypersonic flight). All solutions indicated induced aerodynamic torques on the order of $5-10 \%$ of nominal RCS authority. Additional solution for yaw thrusters was performed at the higher angle of attack of 27 degrees and a sideslip angle of 10 degrees. This solution indicated aerodynamic coupling into pitch axis of about $10 \%$ of nominal authority. From calculations the main contributor to the moment is the impingement of the thruster-wake interaction feature onto the bottom of the parachute closeout cone (PCC). This moment is in the direction such as to reduce the vehicle's angle of attack.

In the context of the aerothermal analysis of MSL $\operatorname{RCS}^{10}$ several calculations on higher fidelity grids at matching Mach 18.1 condition and with an analogous model were carried out in LAURA and DPLR. ${ }^{15}$ Resultant pressure maps are shown in the figure 21. Pressure in the strong interaction features agreed fairly well between the codes. The pressure distribution in the leeside separated zone had greater variability. LAURA calculation showed $20 \%$ increment in yaw due to aerodynamic interaction, and DPLR calculation indicated $10 \%$ increment. Both codes predicted some aerodynamic interaction with pitch axis due to pressurization of the PCC and change of pressure on the lee side of the capsule. In the case of the LAURA solution pressurization of the leeside and PCC was more significant, predicting near $15 \%$ pitch torque in the direction of reducing incidence, which is consistent with the results of lower-fidelity grid calculations above. DPLR solution predicts $5 \%$ torque in the opposing direction. Variability between codes is one of 

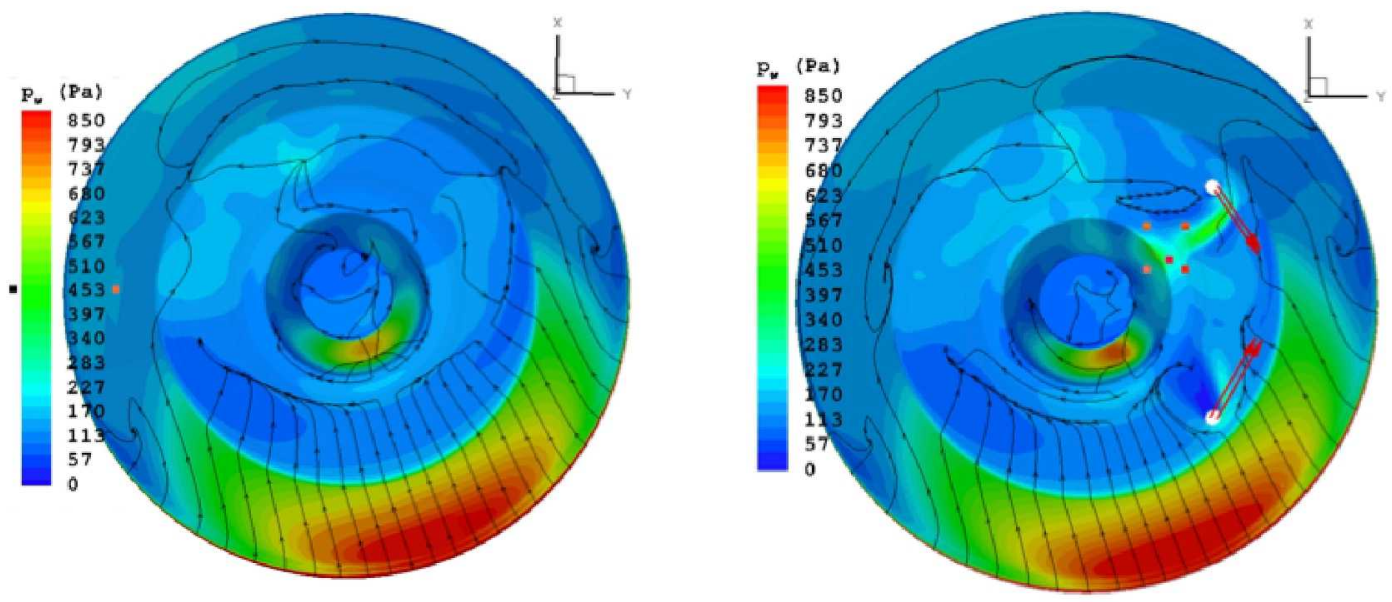

Figure 19. Mach $18 \alpha=27^{\circ}, \beta=10^{\circ}$ baseline solution

Figure 20. Mach $18 \alpha=27^{\circ}, \beta=10^{\circ}$ yaw solution

the measures of uncertainty in these predictions. It should be noted, however, that the codes are solving essentially an analogous model on very similar grids, and any such comparisons do not capture limitations of the model itself.

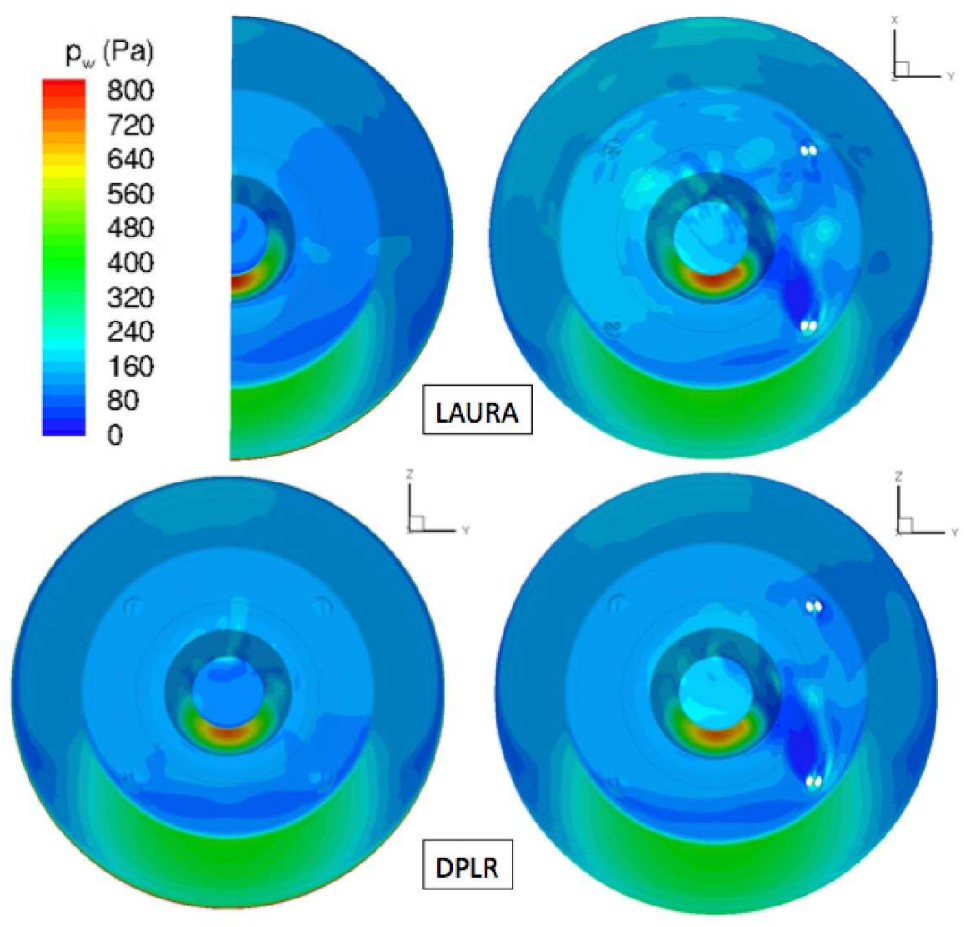

Figure 21. Mach 18 LAURA-DPLR comparisons with and without RCS

\section{B. Supersonic Calculations}

Calculations at Mach 2.5 condition at an angle of attack 19.7 degrees were carried out using FUN3D. Perfect gas laminar air model was used. It has been previously confirmed that the aero-RCS interactions magnitudes at supersonic regime are similar wether Mars atmosphere or air is used in the free-stream. Results are shown for a relatively coarse $1.5 \mathrm{M}$ point grid. Pressure distributions are shown in figures 22 and 23 . Interaction effects computed at this condition were within $10 \%$ of nominal authority. 

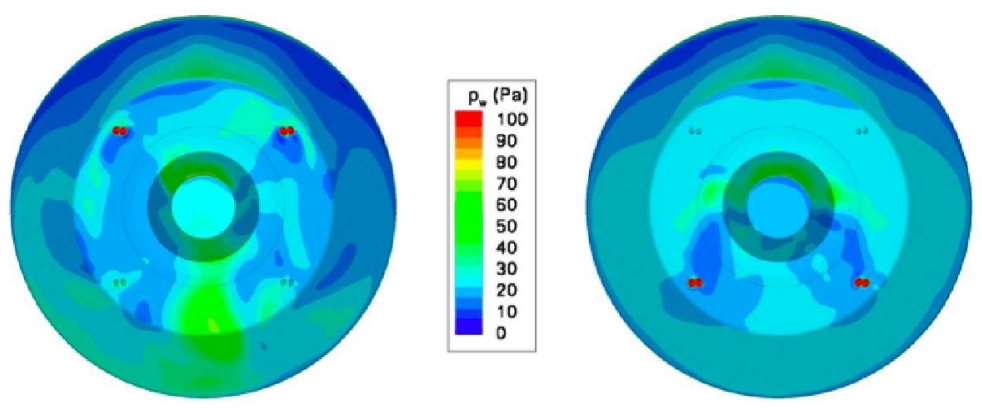

Figure 22. Mach 2.5 FUN3D comparisons with pitch-up and pitch-down RCS (windside at top)
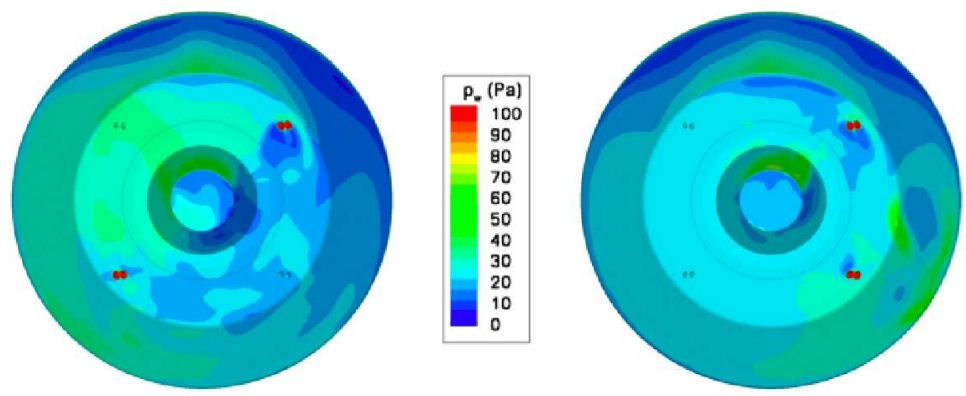

Figure 23. Mach 2.5 FUN3D comparisons with roll and yaw RCS (windside at top)

\section{Transonic Calculations}

Calculations at Mach numbers 1.5, 1.1, 0.9 and 0.7 were carried out with OVERFLOW ${ }^{16}$ code. Flow was modeled as perfect gas with the ratio of specific heats $\gamma=1.29$, representative of the post-shock equivalent gamma for Mach 2.5 flight condition at Mars. Solutions used Baldwin-Barth turbulence model and were quazi - steady state. Solutions were carried out at angle of attack of zero and at $\alpha_{\text {total }}=20^{\circ}$ with the $\alpha_{\text {total }}$ plane entirely in pitch axis, yaw axis and half way between. Results of these calculations showed aerodynamic torques within $10 \%$ of the respective nominal authorities with few minor exceptions. Figure 24 shows Mach profile of a flowfield at Mach 0.7 condition.

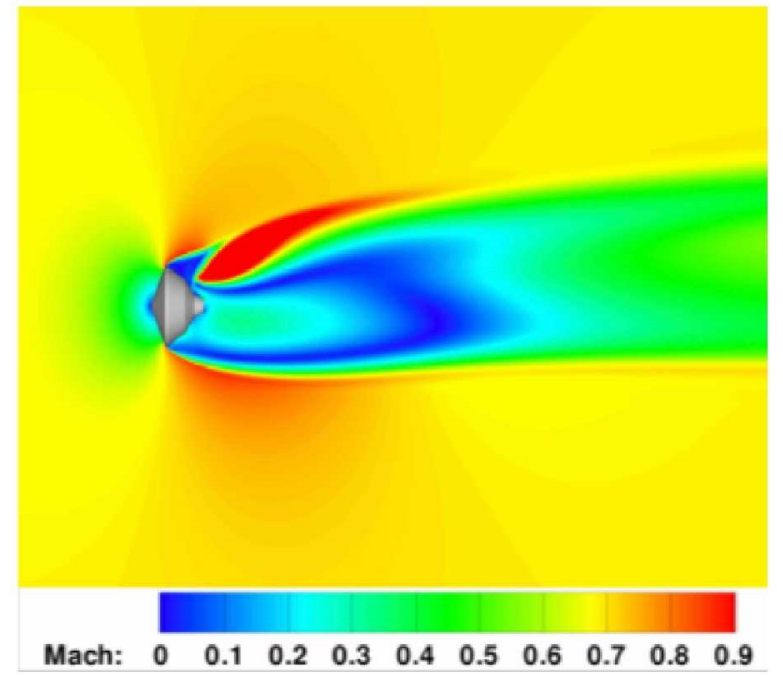

Figure 24. OVERFLOW solution Mach contours with RCS, Mach $0.7, \alpha=0^{\circ}, \beta=0^{\circ}$ 


\section{RCS Design Philosophy}

Because of the high drag requirement, entry capsules typically have high ratio of projected area to volume. This results in a broad subsonic shocklayer that is joined to the massively separated wake by rapidly expanding supersonic shoulder flow as shown in the Figure 1. The influence of the jets on the aftbody surface pressures depends on the local and RCS flow and the thruster size, placement and orientation. Because the aft-cover is shaped with the primary goal to accommodate the payload, structure, cruise stage mounting etc. its role as an aerodynamic surface is frequently viewed as secondary. This can result in the aftshell of the shape, such that there are regions with large moment arms about the CG as shown in the figures 25 and 26. The effect that the changes in pressure distribution due to the RCS activity may have on the capsule moments is difficult to anticipate due to the complexity of the interaction and the uncertainty in analysis tools. Experience with the analysis of the aerodynamic and aerothermal RCS effects has yielded several working paradigms that have been applied to the MSL RCS design. Because the interactions are strongest when the jet is aimed against the oncoming supersonic flow, it is preferred to direct RCS engines with the oncoming flow, or to place them in such a way, that the jet plumes would be contained entirely within the re-circulating region. The latter may not be possible, as the re-circulating regions shape and size may not be adequate. If strong interactions between the jet and surrounding flow are unavoidable, it may be possible to have such interactions that result in favorable capsule moments (ex. figure 27), or almost no moments. Mapping the surface moment arms can help understand where the interactions can be favorable. Figure 29 illustrates the recent MSL RCS design that follows this philosophy with good success. When compared to the one, shown in the figure rcs:before, the reduced effects of the jets on the surface pressures are evident. Generally, achieving the same ideal control torque by a smaller engine with a larger moment arm should reduce the interactions, and should be pursued if possible.
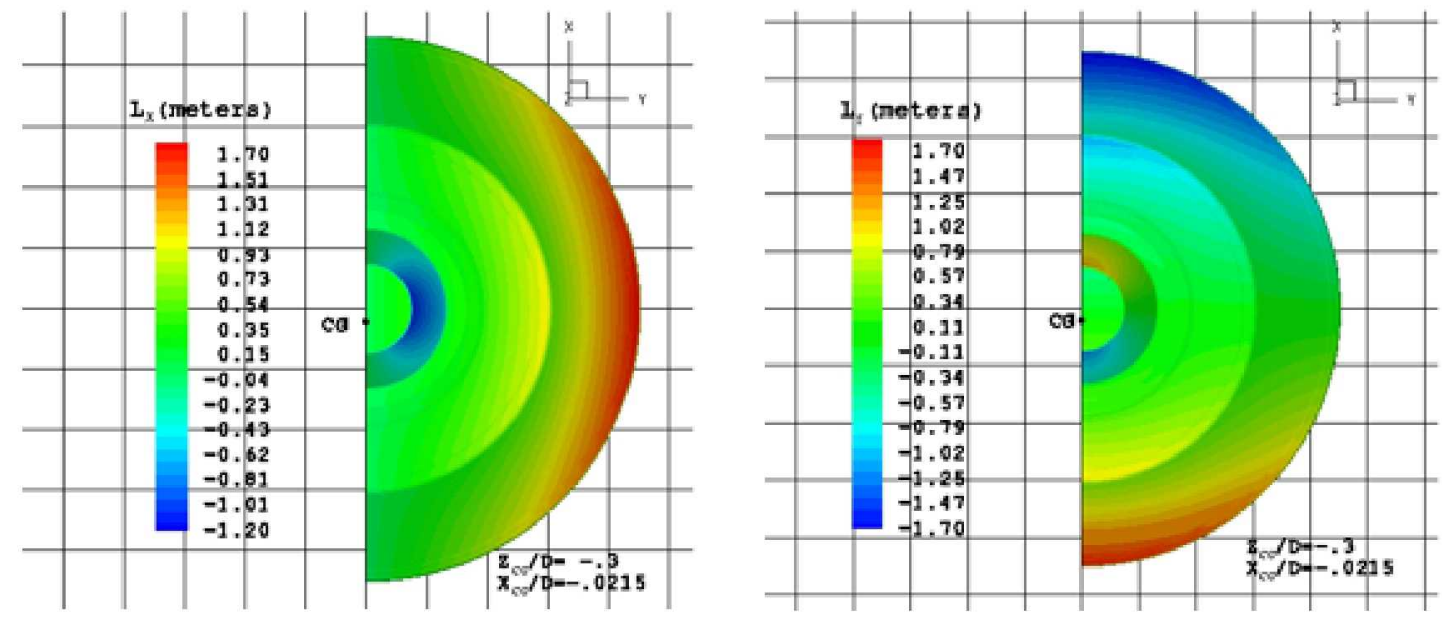

Figure 25. X-moment arm lengths for each point Figure 26. X-moment arm lengths for each point on the MSL backshell w.r.t. the CG on the MSL backshell w.r.t. the CG 


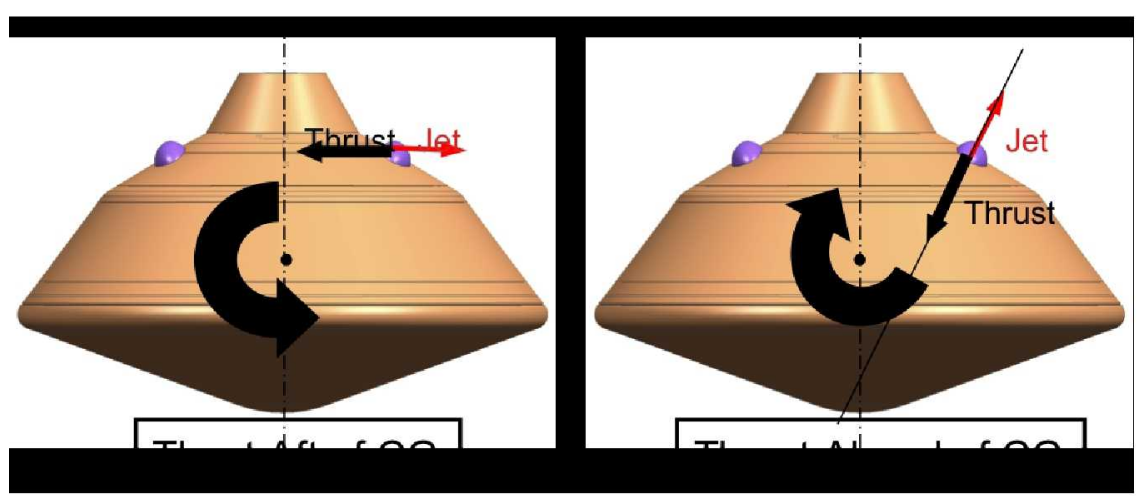

Figure 27. Thrust direction options

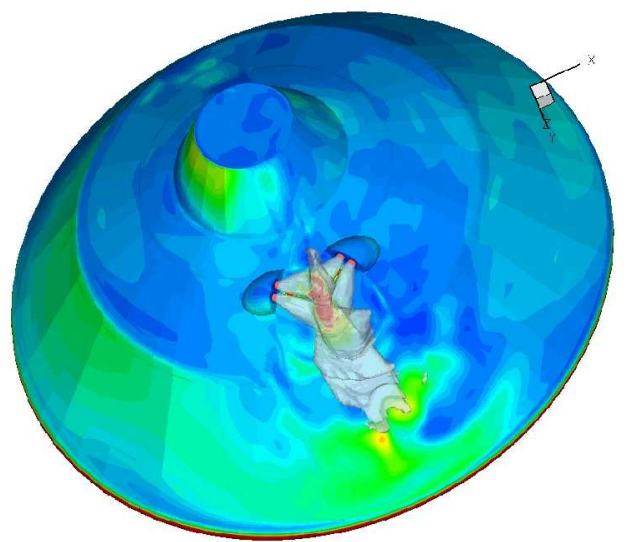

Figure 28. Predicted surface pressures before re- Figure 29. Predicted surface pressures after redesign

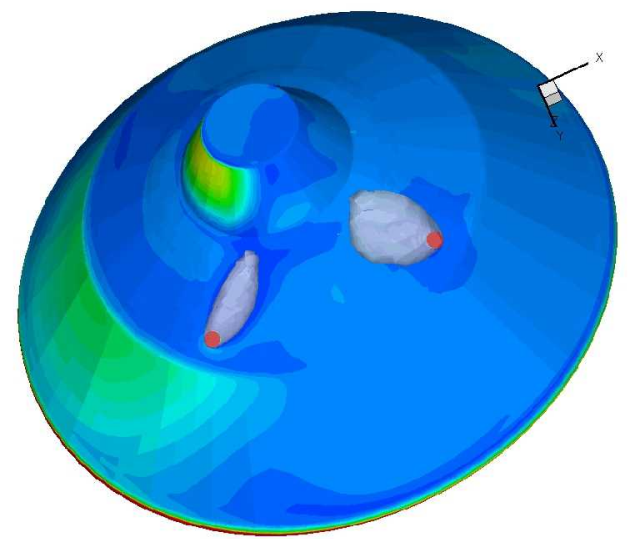
design

\section{Conclusions}

Design concerns and considerations for Mars Science Laboratory entry vehicle reaction control system (RCS) are presented. It is demonstrated through analysis that RCS-aerodynamic interactions during entry can be significant. The flight conditions during which the largest interactions may be expected were identified. It is determined that large aero-RCS interference torques can be developed during hypersonic flight where dynamic pressure is high. Numerical methods used to assess these effects are being developed and tested. Accurate characterization of RCS interference aerodynamics through experiments is challenging partly because the regime of interest is hypersonic flight.

MSL RCS has evolved under the influence of aerodynamic, aerothermodynamic and other constraints. Interaction of RCS and wake flowfield for one of the screened thruster layouts was predicted to negate all of the nominal authority in yaw channel, rendering that RCS useless. Unexpected reduction or increase of thruster efficacy can interfere with flight software, reducing the performance of the MSL EDL system and is, therefore, undesireable. In the course of the analyses of the RCS effects several off-designs were explored to gain understanding of the design space. Based on this understanding, paradigms for RCS design were formed. These paradigms are consistent with the layout philosophy of the control system of the Viking landers. It is shown through CFD analysis that the RCS aerodynamic interaction effects should depend greatly on the jet location and direction. Understanding, gained from this work has been applied to MSL flight vehicle. All analyses of the final MSL RCS indicate low to moderate levels of aero-RCS interference. Wind tunnel tests are needed to increase understanding of the phenomena and develop and validate CFD tools. In this regard, the need for instrumented flights is especially evident. In addition, CFD has been shown to be a tool that can be used in mapping out the aerodynamic and aerothernodynamic design space for RCS interactions on Mars entry vehicles. 


\section{Acknowledgements}

The authors would like to acknowledge the contribution of Victor Lessard of NASA Langley for his help with structured computational grids for MSL. Authors also thank Pieter Buning of NASA Langley for his help with the application of OVERFLOW code to RCS calculations.

\section{References}

${ }^{1}$ Dyakonov A. A. et. al., Analysis of Effectiveness of Phoenix Entry Reaction Control System, AIAA Paper 2008-720, Honolulu, Hawaii, August 2008.

${ }^{2}$ Jones, R. A. and Hunt J. L., Effects of Cavities, Protuberances, and Reaction-Control Jets on Heat Transfer to the Apollo Command Module, NASA TM X-1063, 1965.

${ }^{3}$ Lee D. B., Bertin J. J. and Goodrich W. D., Heat-Transfer Rate and Pressure Measurements Obtained During Apollo Orbital Entries, NASA TN D-6028, 1970.

${ }^{4}$ Adkins E.J. et. al., Entry Vehicle Control, NASA SP-8028, 1969.

${ }^{5}$ Blake W. W. and Polutchko R. J., Hypersonic Experimental Aerodynamic Characteristics of Viking Lander Capsule, Martin Marietta, TR-3709012, 1970.

${ }^{6}$ Siemers P. M., Personal communication, NASA Langley, 2008.

${ }^{7}$ Scallion W. I., Space Shuttle Reaction Control System - Flow Filed Interaction During Entry, Proceedings of the NASA Aerodynamics Symposium, Williamsburg, VA, April 27-30 1993.

${ }^{8}$ Schoenenberger M. et. al. Aerodynamic Challenges for the Mars Science Laboratory Entry Descent and Landing, AIAA Paper 2009-3914, San Antonio, Texas, June 2009.

${ }^{9}$ Edquist K.T. et al, Aerothermodynamic Environments Definition for the Mars Science Laboratory Entry Capsule, AIAA Paper 2007-1206, Reno, Nevada, January 2007.

${ }^{10}$ Edquist K.T. et al, Aerothermodynamic Design of the Mars Science Laboratory Backshell and Parachute Cone, AIAA Paper 2009-4078, San Antonio, Texas, June 2009.

${ }^{11}$ Buck G. M. et. al. Experimental Measurement of RCS Jet Interaction Effects on a Capsule Entry Vehicle, AIAA Paper 2008-1229, Reno, Nevada, January 2008.

${ }^{12}$ Holmberg N.A. and Faust R.P., Viking '75 Spacecraft Design and Test Summary, Volume 1 - Lander Design, NASA Reference Publication 1027, 1980

${ }^{13}$ Cheatwood, F. M. and Gnoffo, P. A., Users Manual for the Langley Aerothermodynamic Upwind Relaxation Algorithm (LAURA), NASA TM-4674, April 1996.

${ }^{14}$ Gordon, S. and McBride, B. J., Computer Program for Calculation of Complex Chemical Equilibrium Compositions and Applications, NASA Reference Publication 1311, October 1994.

${ }^{15}$ Wright M. J., Candler G. V. and Bose, D., Data-Parallel Line Relaxation Method for the Navier-Stokes Equations, AIAA Journal, Vol.36, No.9, September 1998.

${ }^{16}$ Buning, P.G. et. al, OVERFLOW User's Manual, Version 1.6ab, 26 January 1993, NASA Ames Research Center, Moffett Field, CA, Jan. 1993

${ }^{17}$ Hollis B. R., et. al. Aeroheating Testing and Predictions for Project Orion CEV at Turbulent Conditions, AIAA Paper 2008-1226, Proceedings of AIAA Aerospace Science Meeting and Exhibit, Reno, Nevada, January 2008.

${ }^{18}$ Hollis B. R. and Perkins J. N. Transition Effects on Heating in the Wake of a Blunt Body, JSR Vol. 36, No. 5, SeptemberOctober 1999.

${ }^{19}$ Chapman D. R., Kuehn D. M. and Larson H. K., Prelimimnary Report on Study of Separated Flows in Supersonic and Subsonic Streams, NACA RM A55L14, June 1956.

${ }^{20}$ von Doenhoff A. E., A Preliminary Investigation of Boundary Layer Transition Along a Flat Plate with Adverse Pressure Gradient, NACA TN 639, 1938.

${ }^{21}$ Spaid F. W. and Cassel L. A., Aerodynamic Interference Induced by Reaction Controls, AGARD-AG-173, 1973.

${ }^{22}$ Berger K. T., Aerothermodynamic Testing of the Crew Exploration Vehicle in the LaRC 20-Inch Mach 6 and 31-Inch Mach 10 Tunnels, AIAA Paper 2008-1225, Proceedings of AIAA Aerospace Science Meeting and Exhibit, Reno, Nevada, January 2008.

${ }^{23}$ Pindzola M., Jet Simulation in Ground Test Facilities, AGARDograph, November 1963. 